\title{
Management of coronary sinus ostial atresia in a donor heart during cardiac transplantation
}

Jonathan Price, MD, Neil Galindez, MD, and Matthias Peltz, MD, Dallas, Tex

\author{
From the Department of Cardiovascular and Thoracic Surgery, University of Texas Southwestern Medical Center, \\ Dallas, Tex. \\ Disclosures: Authors have nothing to disclose with regard to commercial support \\ Received for publication Nov 19, 2015; revisions received Feb 15, 2016; accepted for publication Feb 21, 2016; \\ available ahead of print April 7, 2016. \\ Address for reprints: Jonathan Price, MD, 5959 Harry Hines Blvd, POB1, 10th floor, Suite HP10.110, Dallas, TX \\ 75390-8879 (E-mail: jonathan.price@utsouthwestern.edu). \\ J Thorac Cardiovasc Surg 2016;152:e25-6 \\ $0022-5223 / \$ 36.00$ \\ Copyright (c) 2016 by The American Association for Thoracic Surgery \\ http://dx.doi.org/10.1016/j.jtcvs.2016.02.069
}

\section{……… \\ VIDEO}

Video clip is available online.

Persistent left superior vena cava (PLSVC) is the most common congenital thoracic venous anomaly, with a prevalence of $0.3 \%$ to $0.5 \%$ in the general population and $3 \%$ to $10 \%$ in patients with congenital cardiac disease. ${ }^{1}$ Coronary sinus ostial atresia (CSOA) is a rare congenital cardiac anomaly. When present, venous drainage of the heart may be via the Thebesian channels, direct communication of the coronary sinus with the left atrium (LA), or retrograde flow to the right atrium via a PLSVC. ${ }^{1}$ A PLSVC may represent the sole channel of venous outflow for the myocardium, and disruption of this vessel can be deleterious. $^{2,3}$ We present a case of a 67-year-old man who underwent orthotopic heart transplantation from a donor organ with a PLSVC and CSOA.

\section{CASE REPORT}

The patient is a 67-year-old Caucasian man who implantation of a HeartMate II left ventricular assist device (Thoratec, Pleasanton, Calif) as a bridge to decision. After recovery, he was deemed a suitable candidate for of the diagnostic studies and inspection of the donor organ revealed excellent cardiac function without obvious abnormality, and the recipient operation commenced.

During the donor cardiectomy, a PLSVC was identified (Figure 1), which we planned on managing with simple ligation. After completion of the donor cardiectomy, CSOA was noted as well. The coronary sinus appeared to have a muscular blind end some distance proximal to the ostium, precluding the possibility of recanalization. We felt the safest approach at this time was to anastomose the PLSVC to the LA. presented with ischemic cardiomyopathy and underwent transplantation, and a donor heart was located. A review

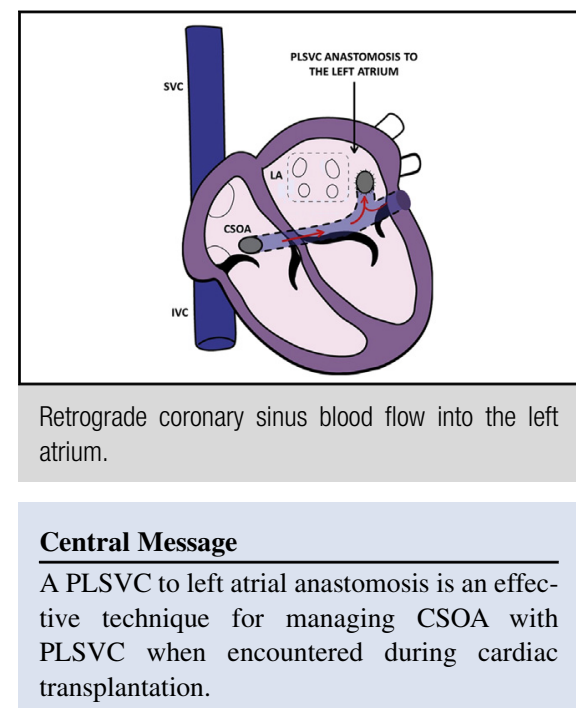

See Editorial Commentary page e27.
Before implantation, an end-to-side anastomosis of the PLSVC to the LA was created anterior to the base of the left atrial appendage (Figure 2). The procedure was completed using a standard bicaval technique. The patient was weaned from CPB without difficulty. He recovered well, and was discharged home on postoperative day 9.

Echocardiography performed at 7 months after surgery demonstrated normal left and right ventricular systolic function. Clinically, there was no evidence of significant right-to-left shunt, and his room air $\mathrm{O}_{2}$ saturation was $98 \%$. Coronary angiography during his first annual visit revealed coronary venous drainage into the LA, suggesting that at least some the cardiac venous drainage was dependent on the PLSVC (Video 1).

\section{DISCUSSION}

To date, there have been 44 cases of CSOA with PLSVC reported in the English literature. Almost 50\% of patients with CSOA had an accompanying PLSVC. ${ }^{3}$ The literature demonstrates the need for maintaining patency of the cardiac venous outflow channels when CSOA is diagnosed. Once cardiac venous outflow is obstructed, immediate engorgement of the cardiac veins and myocardial tissue may become evident and myocardial contractility may be compromised. ${ }^{2,4}$ If venous outflow is not restored, then myocardial hemorrhage and infarction may ensue, ultimately resulting in death. 


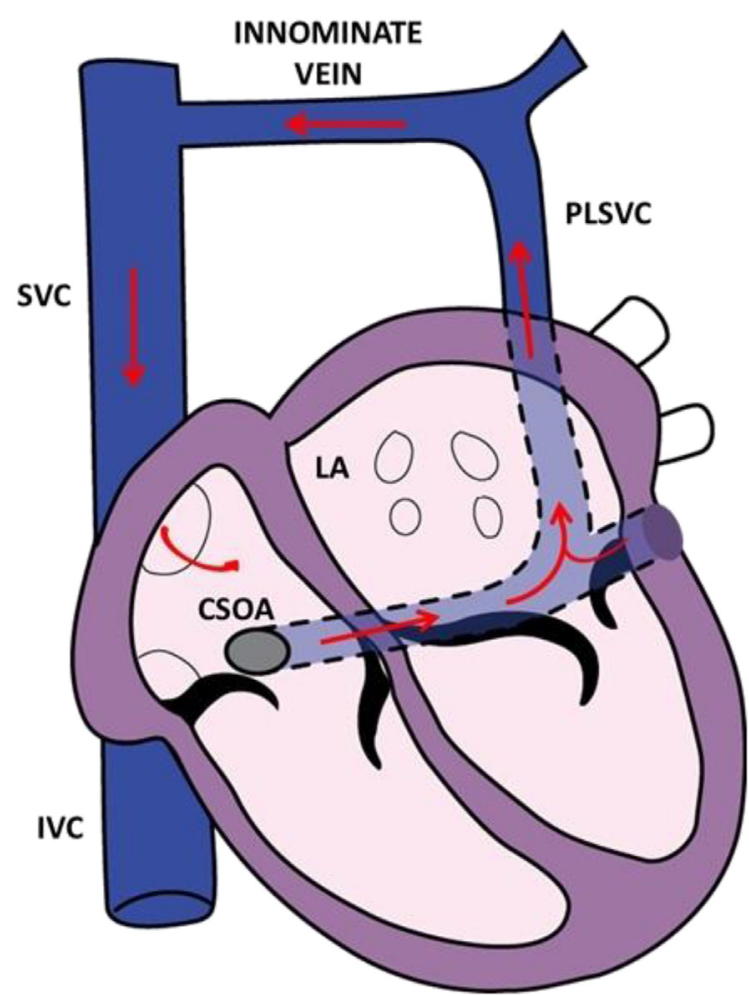

FIGURE 1. Donor retrograde coronary sinus blood flow into the right atrium via the PLSVC in the setting of CSOA. SVC, Superior vena cava; $P L S V C$, persistent left superior vena cava; CSOA, coronary sinus ostial atresia; $L A$, left atrium; $I V C$, inferior vena cava.

CSOA may exist as an ostium with a thin, translucent membranous covering, which may be excised to maintain venous blood flow. ${ }^{5}$ In other cases, the coronary sinus ends as a blind pouch, with variable distance from the normal location of the ostium. In this scenario, a more elaborate procedure may be needed to maintain adequate cardiac venous drainage. Few methods have been described for maintaining venous drainage of the heart in this scenario; however, establishing direct or indirect communication between the coronary sinus and LA seems to be an effective strategy for treating this anomaly.

There has been only 1 previously reported case of CSOA in a donor heart during cardiectomy. ${ }^{5}$ In that case, maintenance of anterograde cardiac venous flow could be performed through excision of a thin membrane covering the ostium of an otherwise normal coronary sinus. In our patient, inspection of the coronary sinus demonstrated a thick, muscular-appearing blind end to the vessel that could not be recanalized. Given the significant chance that the PLSVC represented the sole means of cardiac venous

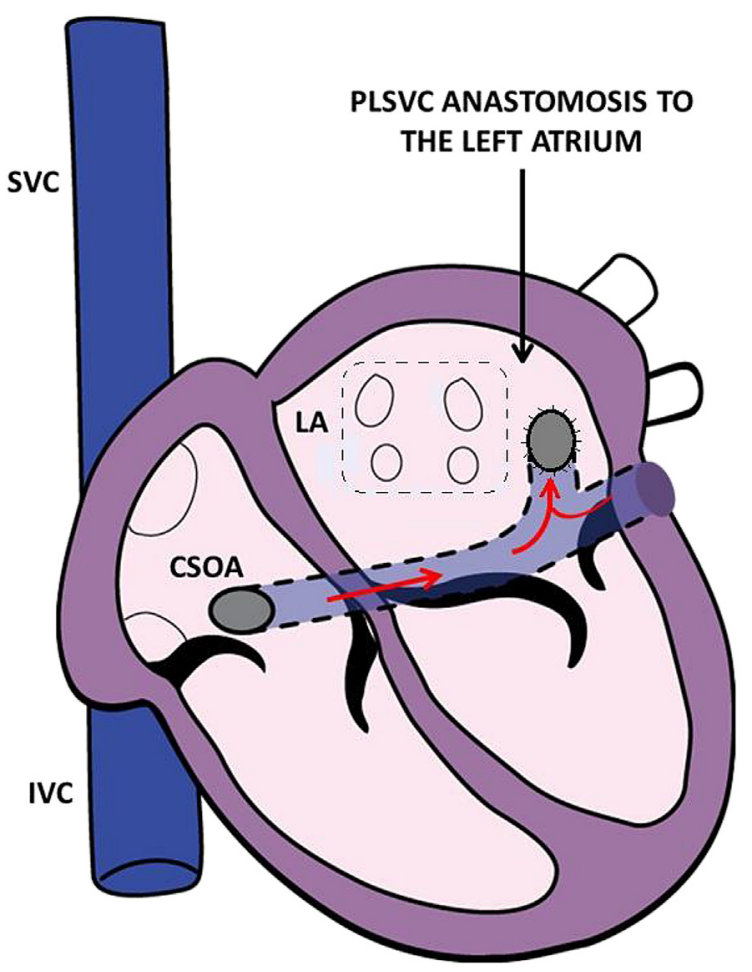

FIGURE 2. Recipient coronary sinus blood flow directly into the LA after end-to-side anastomosis. SVC, Superior vena cava; PLSVC, persistent left superior vena cava; $C S O A$, coronary sinus ostial atresia; $L A$, left atrium; $I V C$, inferior vena cava.

egress, simple ligation of the vessel was not considered a reasonable alternative. We felt that the safest option at that time was to ensure adequate venous drainage via a direct connection of the remnant of the PLSVC to the LA. This method of maintaining flow through the coronary sinus has not been previously described in the transplantation literature, but appears to be a suitable technique for coronary sinus drainage when CSOA and a PLSVC are encountered during a donor cardiectomy.

\section{References}

1. Mantini E, Grondin CM, Lillehei CW, Edwards JE. Congenital anomalies involving the coronary sinus. Circulation. 1966;33:317-27.

2. Jha NK, Gogna A, Tan TH, Wong KY, Shankar S. Atresia of coronary sinus ostium with retrograde drainage via persistent left superior vena cava. Ann Thorac Surg. 2003;76:2091-2.

3. Yokota M, Kyoku I, Kitano M, Shimada I, Mizuhara H, Sakamoto K, et al. Atresia of the coronary sinus orifice: fatal outcome after intraoperative division of the drainage left superior vena cava. J Thorac Cardiovasc Surg. 1989;98:30-2.

4. Fulton JO, Mas C, Brizard CP, Karl TR. The surgical importance of coronary sinus orifice atresia. Ann Thorac Surg. 1998;66:2112-4.

5. Buckels NJ, Vosloo S, Rose AG, Odell JA. Donor heart coronary sinus ostium atresia in a successful cardiac transplant. Ann Thorac Surg. 1992;53:1096-7. 